\title{
Effect of Cooling Conditions on Mechanical and Microstructural Behaviours of Friction Stir Processed AZ31B Mg Alloy
}

\author{
Sankar Ramaiyan, Rathinasuriyan Chandran, Senthil Kumar Velukkudi Santhanam \\ Department of Mechanical Engineering, Anna University, Chennai, India \\ Email: sankphd2015@gmail.com, rathinasuriyanphd@gmail.com,vssk70@gmail.com
}

How to cite this paper: Ramaiyan, S., Chandran, R. and Santhanam, S.K.V. (2017) Effect of Cooling Conditions on Mechanical and Microstructural Behaviours of Friction Stir Processed AZ31B Mg Alloy. Modern Mechanical Engineering, 7, 144-160.

https://doi.org/10.4236/mme.2017.74010

Received: August 30, 2017

Accepted: November 25, 2017

Published: November 28, 2017

Copyright $\odot 2017$ by authors and Scientific Research Publishing Inc. This work is licensed under the Creative Commons Attribution International License (CC BY 4.0).

http://creativecommons.org/licenses/by/4.0/

\begin{abstract}
Friction stir processing (FSP) is an important microstructural alteration process used recently in the engineering field. Grains alteration and hence the mechanical properties of the possessed zone are controlled by the temperature, heating and cooling rate. In this work, AZ31B magnesium samples were friction stir processed in three different cooling conditions like air, water and cryogenic (liquid nitrogen) cooling. $1000 \mathrm{rpm}$ and $60 \mathrm{~mm} / \mathrm{min}$ were kept constant as tool rotation speed and traverse speed respectively in all the three mediums. The consequence of these conditions on thermal fields, axial force, resulting grain structure and mechanical properties was studied. It is found that the cryogenic treated friction stir processed samples exhibit fine grain structures and hence offer better mechanical properties than the air and water cooled processed samples.
\end{abstract}

\section{Keywords}

Friction Stir Processing, AZ31B Magnesium Alloy, Cryogenic Coolant, Liquid Nitrogen and Mechanical Properties, Axial Force,

Submerged Friction Stir Processing

\section{Introduction}

Friction stir Processing (FSP) is developed and introduced to the global scenario in 1999 [1]. FSP basically involves the same concept as Friction Stir Welding (FSW) which is a solid state processing technique for microstructural modification and improvement of mechanical properties [2] [3]. In FSP, a non-consumable rotating tool with a shoulder and a pin is embedded in the work piece and traversed along the desired path for localized microstructural variation for specific 
property improvement in the handled zone, arising from deep plastic deformation, blending and thermal presentation of the metal cooling in manufacturing processes which is known to improve a tool life and surface finish [4] [5]. Magnesium and its alloys are the lightest essential materials as they less in weight by $40 \%$ compare to aluminum alloy and $78 \%$ to steel. $\mathrm{Mg}$ alloys are known for excellent specific strength, excellent sound damping capabilities, useful cast-ability, good machinability, excellent formability, valuable electromagnetic interference shielding, and recyclability, having applications in aerospace, automobile and ship building industries. They have better corrosion resistant than aluminum alloys [6] [7]. There are some advantages associated with cooling which are related mostly to microstructure enhancements; that FSP has been improved as superior to AZ31B magnesium alloy. Darras et al. [8] have investigated the mechanical properties and microstructure behavior of FSP under water medium, and concluded that this is an effective technique which modifies the grain size and enhances the tensile properties of AZ91 magnesium alloy. Prakash et al. [9] have conducted the experiment on FSP to applied liquid nitrogen coolant on the processed sample for investigation of temperature, torque and grain size improvements and comparing with FSPed air medium samples. The results shows decrease in the ultimate tensile strength, impact strength as also increase in the percentage of elongation at cryogenic temperature achieved by cryogenic pre cooling [10].

Friction Stir processing of AZ31B Mg alloy during cryogenic cooled samples achieved finer and a better homogeneous grain size than the FSPed air Samples. Recently very few researchers have used liquid nitrogen coolant on FSW/FSP samples, few study of thermal history, mechanical properties and microstructure analysis at cryogenic coolant (liquid nitrogen), considered as suitable technique for application to aerospace and automotive which are run at low temperature place [11] [12]. The present study investigates the hot-rolled AZ31B magnesium alloys was subjected to FSP in air, water and cryogenic coolant respectively. A result of the thermal histories of the two FSPed zones was made. Investigation of the effect of cooling conditions on the microstructure, mechanical properties and axial load was also made.

\section{Material and Experiment Methods}

FSP was conducted using a 3 axis servo control friction stir welding machine. A special fixture was designed and built to hold the samples. Table 1 list the chemical composition of AZ31B Mg alloy.

The tool used in this work has a scrolled shoulder with a diameter of $24 \mathrm{~mm}$, and a three stepped square pin total height of $5.8 \mathrm{~mm}$, slightly shorter than the

Table 1. Chemical composition of magnesium alloy AZ31B.

\begin{tabular}{cccccccc}
\hline Element & $\mathrm{Zn}$ & $\mathrm{Mn}$ & $\mathrm{Si}$ & $\mathrm{Fe}$ & $\mathrm{Cu}$ & $\mathrm{Ni}$ & $\mathrm{Mg}$ \\
\hline Percentage & 0.71 & 0.32 & 0.08 & 0.005 & 0.05 & 0.005 & Balance \\
\hline
\end{tabular}


thickness of the plate. Rodrigues et al. [13] have concluded that the conical shoulder produced a larger grain size with a small number of coarsened causes as disparate to the welds done with the scrolled shoulder, which exhibited a fine grain size with many coarsened precipitates. The tool rotational speed $(w)$ was $1000 \mathrm{rpm}$ and traverse speed (v) was $60 \mathrm{~mm} / \mathrm{min}$. The tilted angle was $2^{\circ}$ with respect to the $\mathrm{z}$ axis of the FSP machine. Three different procedures were considered for investigating the effect of submerging on the process. These were FSP in air, submerged friction stir processing (SFSP), and cryogenic Friction Stir Processing (CFSP). Water and cryogenic coolant were selected considering their high heat capacity which allows for high heat absorption. These medium were used for investigating the effect of the initial temperature of the submerging environment. The complete experimental set-up and a closer look at the fixture and the FSP tool are shown in Figure 1.

Thermocouples (T1) and (T2) were used for measuring the temperatures at two different locations within the sample during friction stir processing. The mechanical properties and microstructural investigations were done in the middle of FSP samples. Four zones have been identified on the basis of microstructure characterization. These were base material (BM) heat affected zone (HAZ) thermo-mechanical affected zone (TMAZ) and stir zone (SZ). Pouring cryogenic coolant on the processed samples resulted in the achievement of pre cooling. Cryogenic cooling has several advantages applied to changes in the enrichment life of the tool, surface finish and the mechanical properties. The area where it is to be cooled and reached to the target value of $10^{\circ} \mathrm{C}$ till then Cryogenic (liquid nitrogen) coolant is poured. This temperature drop ensured FSP starting temperature would be seen at around $0^{\circ} \mathrm{C}$ by the state of the process. The setup temperature during the pre-cooling phase was maintained by the thermocouples.

The tensile test was conducted by an INSTRON universal testing machine having a capacity of $50 \mathrm{kN}$. A standard tensile test specimen $20 \mathrm{~mm}$ in length and a width of $6 \mathrm{~mm}$ was cut using wire-cut EDM through the ASTM standard E 2448. The tensile specimen used for conducting experiments and the dimension of the specimen used are presented in Figure 2.

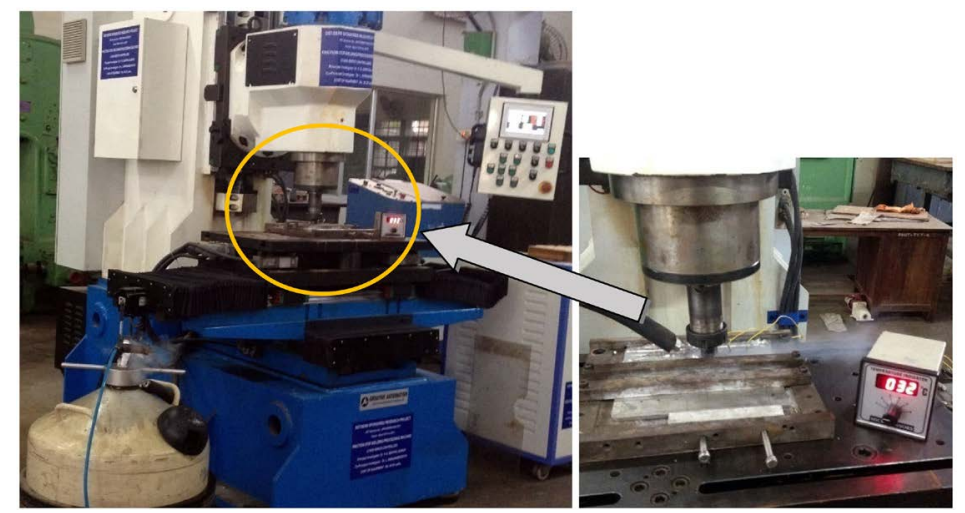

Figure 1. Close up view of sample prior to processing and applied cryogenic coolant. 

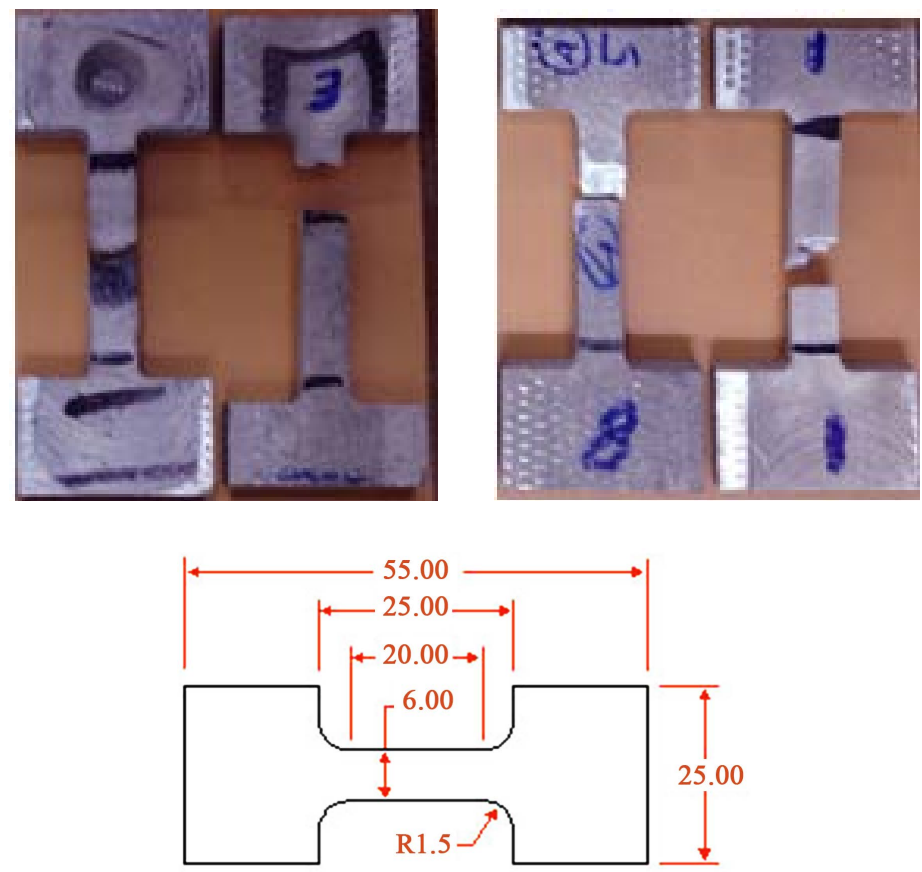

All dimensions are in mm (ASTM E2448)

Figure 2. Tensile samples geometry used in this paper.

The experimental results obtained are presented in Table 2. The parameters, namely, \% elongation and UTS were measured by using a computer interface.

\section{Results and Discussion}

\subsection{Temperature Measurements}

Figure 3 shows the experimental setup of two different locations of the two thermocouples (T1) and (T2). Figure 4(a) and Figure 4(b) provides a comparison of the temperatures recorded through the in FSP in air, submerged FSP and cryogenic FSP samples at a constant rotational and traverse speed. The graph shows the significant difference between the peak temperatures of the three samples.

The thermocouple (T1) recording of the FSP sample in air reached a peak temperature of $283^{\circ} \mathrm{C}$ and gradually decreased around $80^{\circ} \mathrm{C}$ for more than 70 seconds. In contrast, the SFSP and CFSP samples were reached only $162^{\circ} \mathrm{C}$ and $110^{\circ} \mathrm{C}$. The thermocouple (T2) recording of the FSP sample in air reached a peak temperature of $290^{\circ} \mathrm{C}$ and gradually decreased around $60^{\circ} \mathrm{C}$ for more than 50 seconds. In contrast, the SFSP and CFSP samples were reached only $169^{\circ} \mathrm{C}$ and $110^{\circ} \mathrm{C}$ which steadily decreased $40^{\circ} \mathrm{C}$ and $20^{\circ} \mathrm{C}$. As resulting earlier stated, water and liquid nitrogen has a higher heat capacity than air which causes an increase in cooling rate and a decrease in peak temperature in water and cryogenic FSP compared to these in air FSP. Limiting the heat input into the processed sample by increasing the cooling rate was proven to limit the grain growth in the processed sample, thus achieving better mechanical and microstructural proper- 

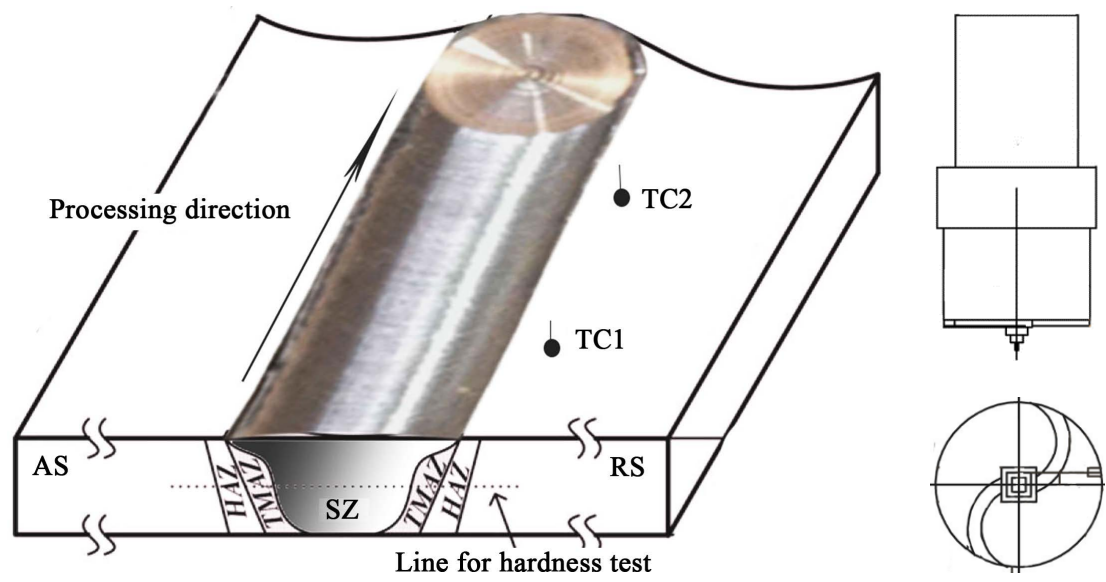

Figure 3. Schematic illustration of friction stir processing.

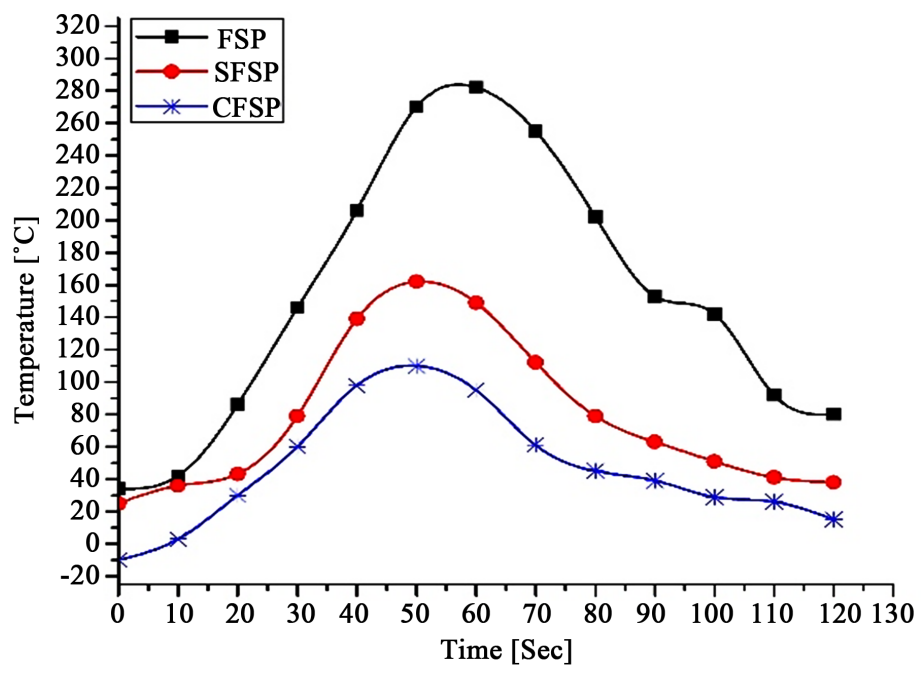

(a)

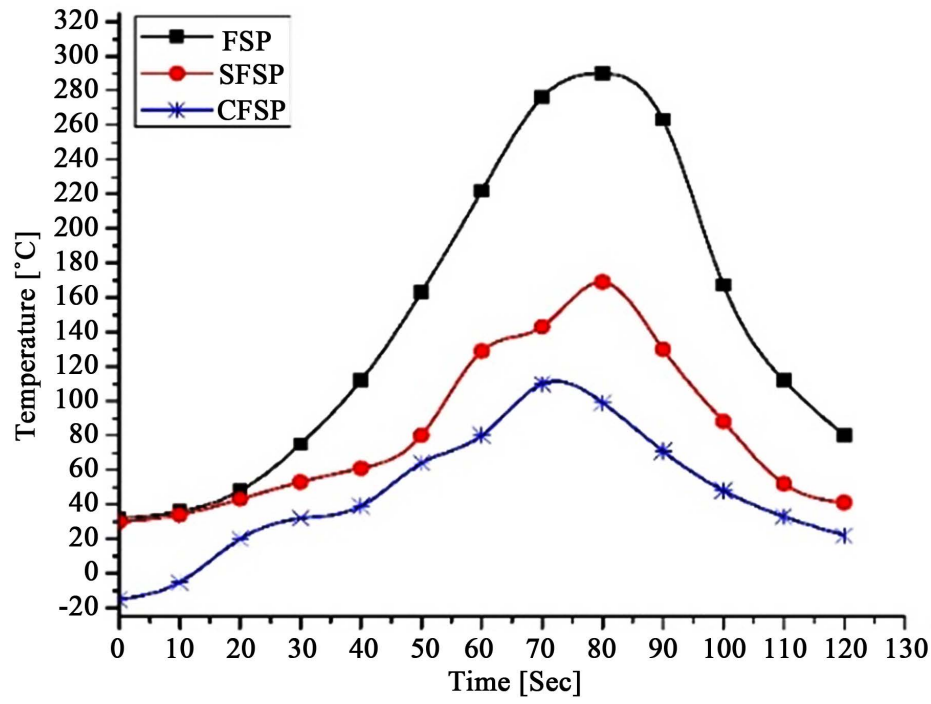

(b)

Figure 4. Comparison of temperature noted between in FSP, SFSP and CFSP. (a) Thermocouple $\left(\mathrm{TC}_{1}\right)$; (b) Thermocouple $\left(\mathrm{TC}_{2}\right)$. 
Table 2. Microstructure and strength properties of processed under different temperature conditions.

\begin{tabular}{cccccccccc}
\hline S1. & Type of & $\begin{array}{c}\text { Speed } \\
\text { No }\end{array}$ & $\begin{array}{c}\text { Traverse } \\
\text { process }\end{array}$ & $\begin{array}{c}\text { UTS } \\
(\mathrm{mm} / \mathrm{min})\end{array}$ & $\begin{array}{c}\text { Elongation } \\
(\%)\end{array}$ & $\begin{array}{c}\text { Hardness } \\
(\mathrm{HV})\end{array}$ & $\begin{array}{c}\text { Temp 1 } \\
\left({ }^{\circ} \mathrm{C}\right)\end{array}$ & $\begin{array}{c}\text { Temp 2 } \\
\left({ }^{\circ} \mathrm{C}\right)\end{array}$ & $\begin{array}{c}\text { Average } \\
\text { grain size } \\
(\mu)\end{array}$ \\
\hline 1 & FSP & 1000 & 60 & 208.70 & 17.502 & 87.9 & 282 & 290 & 18.80 \\
2 & SFSP & 1000 & 60 & 244.10 & 23.50 & 109.80 & 162 & 169 & 2.12 \\
3 & CFSF & 1000 & 60 & 221.11 & 26.50 & 89.99 & 110 & 110 & 1.92 \\
\hline
\end{tabular}

ties [14] [15] [16]. Mishra et al. [17] have observed three significant explanations. The first, peak temperature was recorded at the near to SZ and the temperature decreased with increasing distance from the stirred zone. Second, the increase temperature at the edge of the stirred zone from the bottom surface of the plate to the top surface. Third, a maximum temperature of $475^{\circ} \mathrm{C}$ seen close to the corner between the edge of the stirred zone and the top surface. When submerging in water and cryogenic condition the results demonstrate dramatic changes in the thermal variations in the adapted material. Both reduce the duration for the adapted material above a certain temperature along with the reduction of maximum temperature needed. In the heat treatment, during FSP, both factors are considered as tough aspects. The results show attainment of the lowest peak temperature and time consumed above a certain temperature in cryogenic cooling condition.

These results are due to the heat absorption capacity of water, which produces good cooling rate [18]. Upadhyay et al. [19] examined the effect of thermal boundaries on friction stir welding. The cooling rate was higher found to be submerged samples compared to those welded in air. Moreover, SFSW samples achieved a grain size smaller than that in air welded samples. Hofmann and Vacchio et al. [20] used submerging as a technique to increase the cooling rate of the sample and decrease the time it is exposed to high temperature.

Thermal conductivity of the material has a permanent impact on the thermal fields of the processed material. High thermal conductivity leads to non-uniform thermal fields along the FSP path temperature showing increase along the path [21].

\subsection{Tensile Strength}

The stress-strain curves of unprocessed material, in FSP, under water FSP and cryogenic FSP at $1000 \mathrm{rpm}$ and $60 \mathrm{~mm} / \mathrm{min}$ are illustrated in Figure 5. The unprocessed received sample exhibits an elongation of $10 \%$ and an ultimate tensile strength of $250 \mathrm{MPa}$. Following FSP with various combination, the tensile strengths slightly decrease while the elongations increases significantly. Hung et al. [22] report the tensile strength of the received material AZ31-O sample as more than that of the FSP sample, while good ductility was attained with FSP. They also aver that an alteration in grain orientation and retained stress tempted 


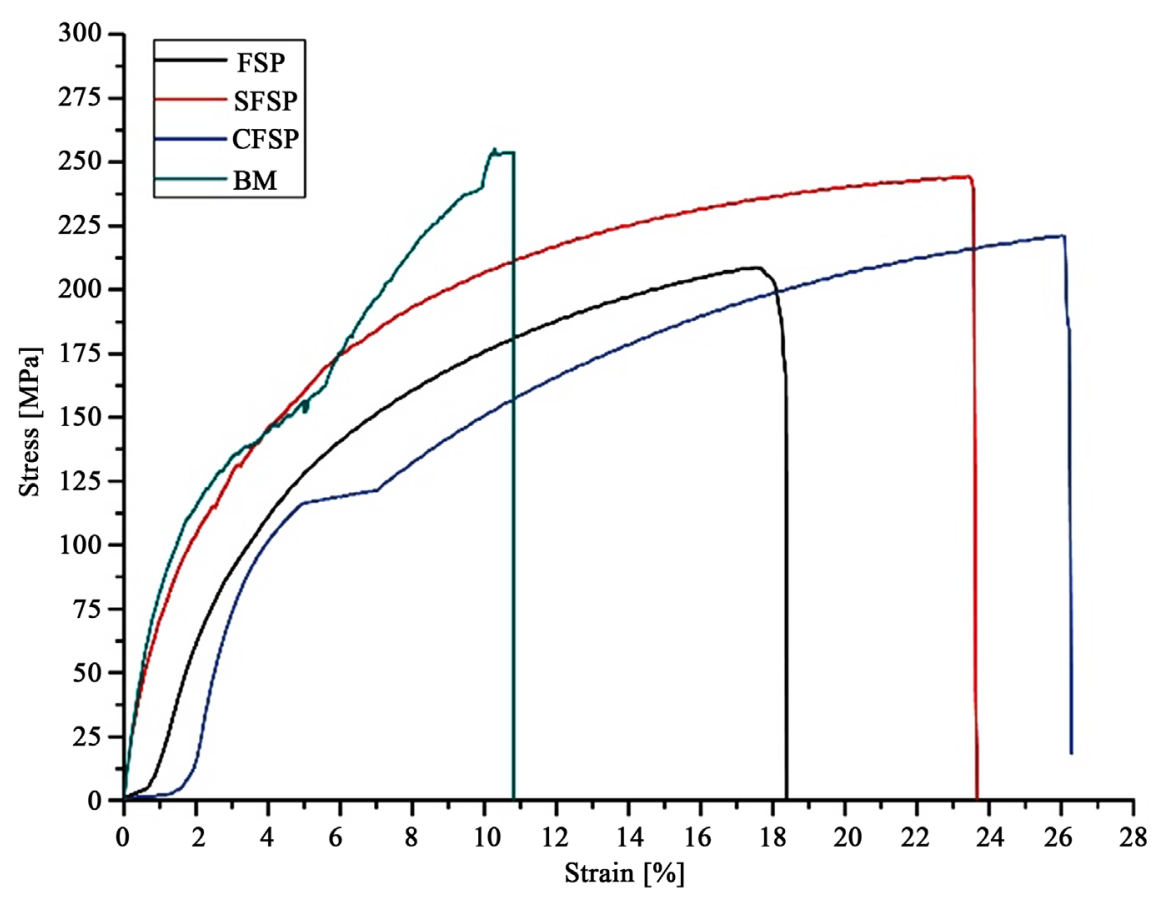

Figure 5. Mechanical properties of BM, FSP, SFSP and CFSP of Stress strain graph.

by FSP leads to unusual Hall-Petch effect. Darras et al. [8] also proved the achievement of a decreasing ultimate tensile strength in the SFSP sample of AZ31B Mg alloy compared to the unprocessed material.

They attributed this to the drastic texture variation during FSP. Figure 6 exposes the effects of the strength, hardness and elongation of the test results of three various processed conditions. From the Figure 6 shows the total range of tensile strength, hardness and elongation \% of the FSP specimen are $191 \mathrm{MPa}$, $87 \mathrm{HV}$ and $18.3 \%$, respectively. As for SFSP, those properties increase to 244 MPa, $109 \mathrm{HV}$ and $23.50 \%$. The CFSP properties slightly decrease in tensile strength $221 \mathrm{MPa}, 90 \mathrm{HV}$ and increase $26.50 \%$ of percentage elongation. The results show SFSP softening the material resulting in small strength and more ductility with implication of better formability at submerged and cryogenic conditions. The highest percentage of elongation were achieved at minimum peak temperature of the samples. This concept could be understood by comparing Figure 4(a) and Figure 4(b).

The results showed SFSP as an effective technique in enhancing formability of AZ31B Magnesium alloy. Submerging in water and cryogenic coolant improves the mechanical properties and elongation \% of the FSP material. Thermal fields and the microstructure that accompanies them are considered to have a direct relationship to this. Those features were seen affected by submerging in water and cryogenic condition. The grain structure after tensile failure remains equiaxed, but the grain size is quite different compared with the initial grain structure. Hung et al. [22] concluded that AZ31-O specimen tensile strength was higher than FSP specimens, where the better ductility was achieved with FSP. 


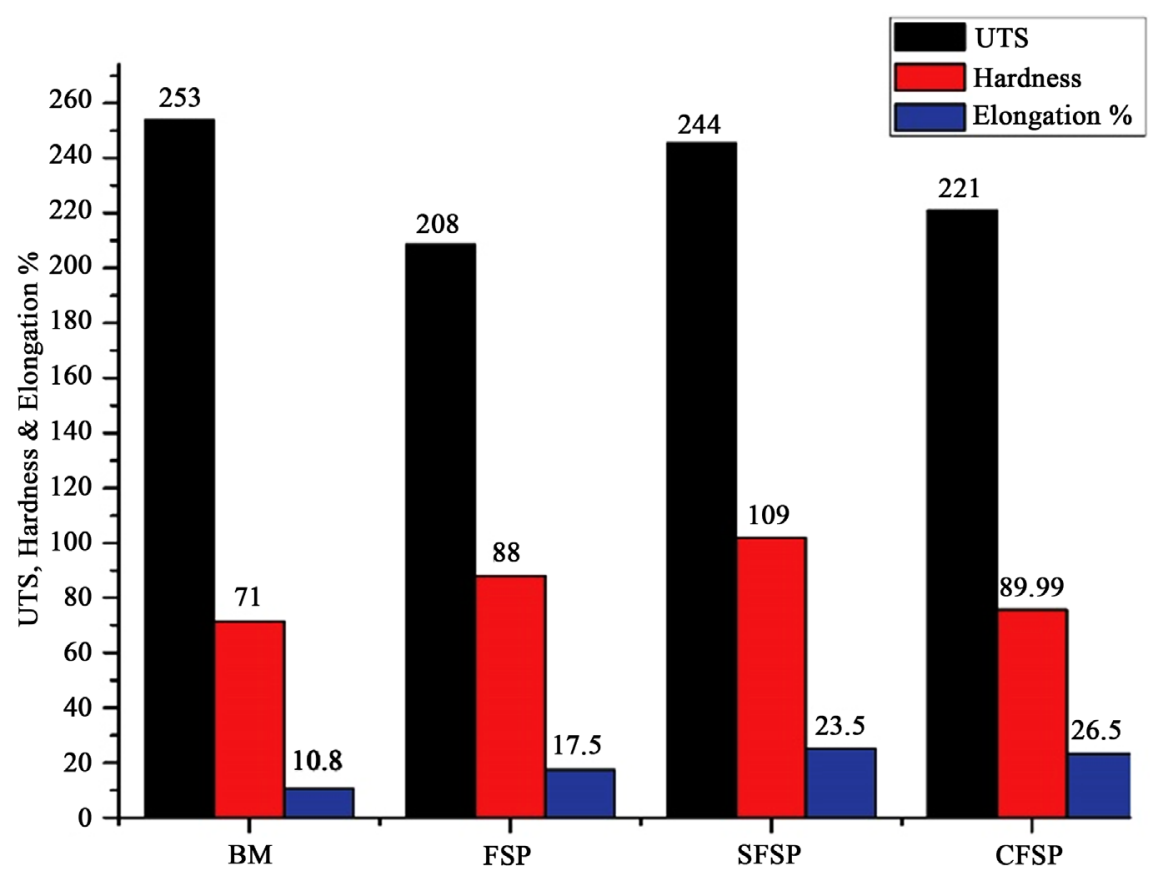

Figure 6. Tensile strength, elongation \% and Hardness of various FSPed condition.

\subsection{Macrostructure}

Figure 7 shows the top surface and cross-section appearance of FSP in air, SFSP and CFSP AZ31B magnesium alloys. The figure, shows the processed zone having good formability and excellent appearance without macro defects such as galling, void and excessive flash. However, in comparison with Figures 7(a)-(c), the FSP specimen is seen creating excessive flash, especially on the retreating side (RS), while the surface of the CFSP AZ31B specimen exhibits very smooth compare to other samples. Ammouri et al. [10] have reported the achievement of the very good surface finish than FSP samples by CFSP samples.

\subsection{Micro Hardness}

Micro-hardness was measured across the processed zone mid thickness region using Vicker's testing machine. The values are shown in Figure 8. The average hardness of the BM is seen as around $71 \mathrm{HV}$. Stir zone $109 \mathrm{HV}$ shows the highest hardness of SFSP specimen, decreasing at both side. The hardness in the HAZ and TMAZ on the advancing side (AS) is slightly higher than that on the retreating side (RS). The average hardness of the SFSP specimen is much higher in comparison result the FSP and CFSP specimens, which are $87 \mathrm{HV}$ and $89 \mathrm{HV}$, respectively. Fang et al. [23] reported the achievement of the highest hardness in submerged condition when compared with FSP and CFSP. Hardness measured in rolled AZ31B Mg alloy $6 \mathrm{~mm}$ thick FSW joints exhibited the higher values for the hardness values of the nugget compared to the BM [24]. The decrease the peak temperature was also seen as providing fine recrystallized grain size and thereby improved hardness. These are two main reasons for the improved hardness of stir zone. Firstly, since the grain size of stir zone is much finer than that 


\begin{tabular}{|c|c|c|c|}
\hline Type & Processed Sample view & Macrostructure of cross section view & Summary \\
\hline FSP (a) & 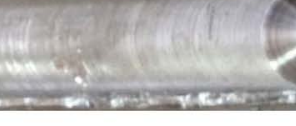 & & $\begin{array}{l}\text { Defect free, it produced } \\
\text { excessive flash }\end{array}$ \\
\hline SFSP (b) & & & $\begin{array}{l}\text { No defect, it produced } \\
\text { onion-ring patterns. }\end{array}$ \\
\hline CFSP (c) & & & $\begin{array}{l}\text { Defect free, it exhibit } \\
\text { very smooth surface quality }\end{array}$ \\
\hline
\end{tabular}

Figure 7. Surface view and traverse cross-section of the FSP, SFSP and CFSP condition.

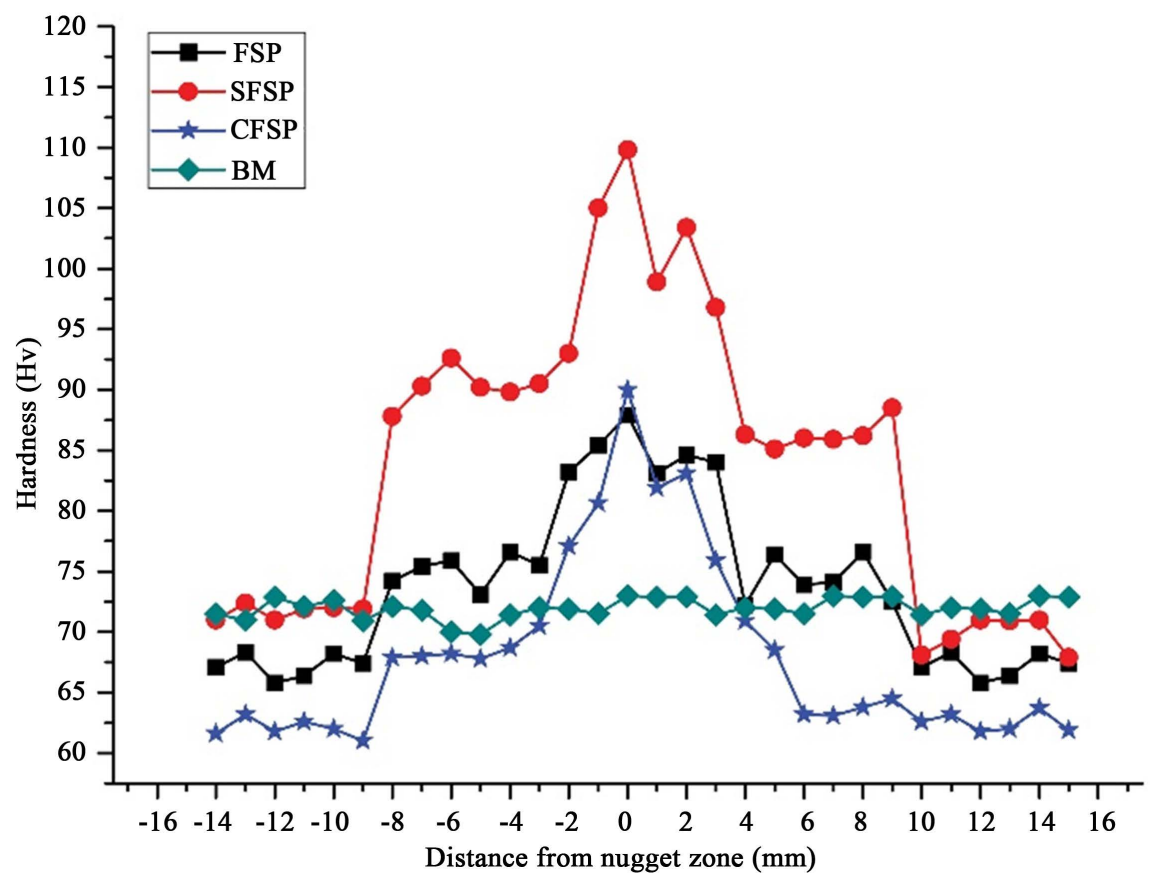

Figure 8. Micro-hardness curve across the processed zone of FSP, SFSP and CFSP.

of base metal, grain refinement plays an important role in material strengthening, secondly the small particles of intermetallic compounds are also a benefit to hardness improvement [25].

\subsection{Microstructure}

Figure 9(a) and Figure 9(b) Shows the microstructure of the received material analyzed by using an optical microscope (OM) and scanning electron microscopy (SEM) images. Coarse and in homogeneous grain structure with lots of voids was observed in the parent material. The microstructure of the FSP sample re- 


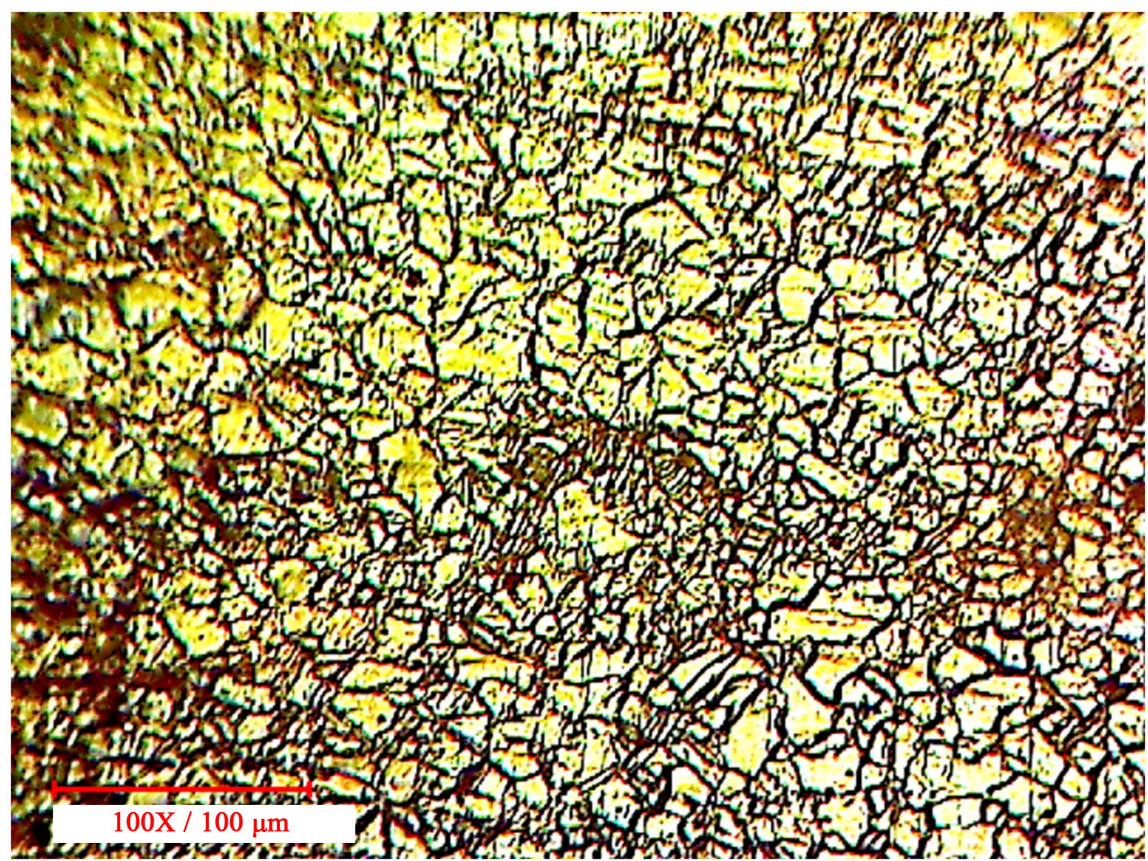

(a)

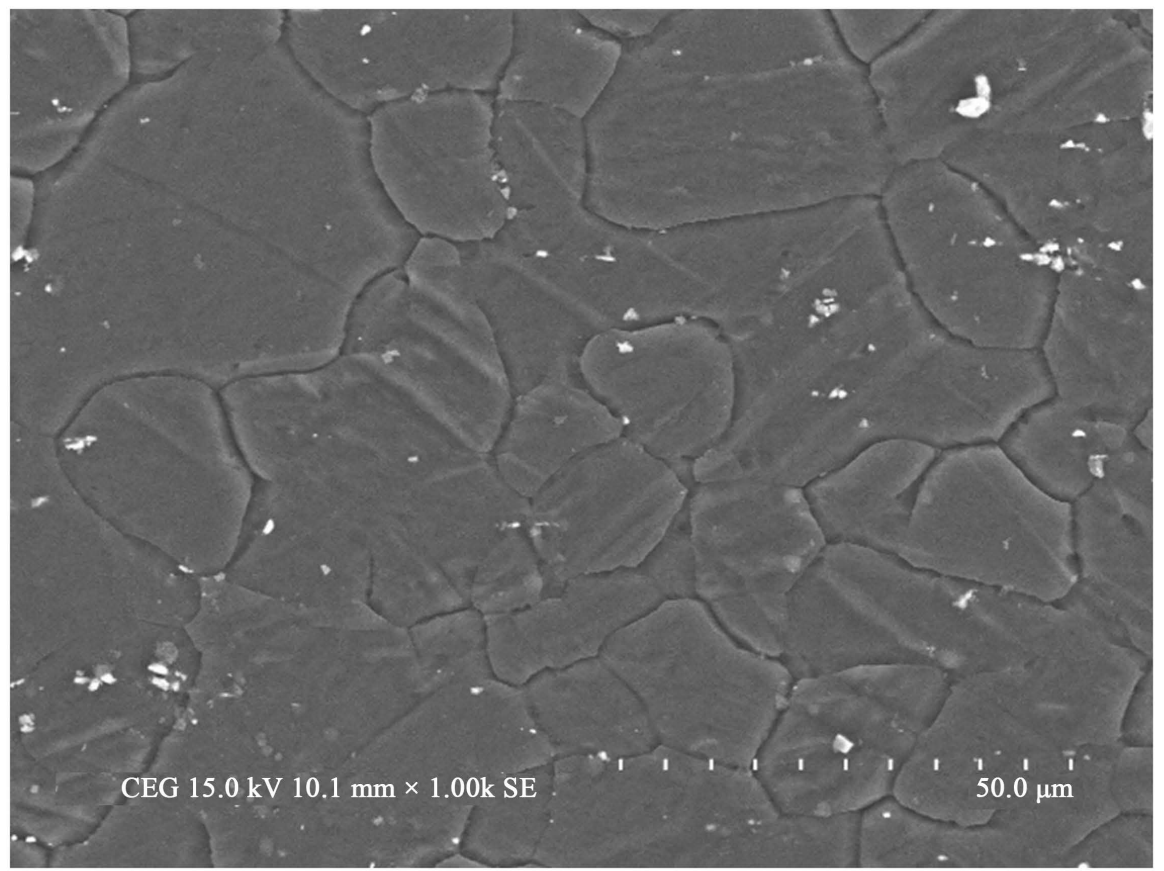

(b)

Figure 9. (a) Optical micrographs and (b) SEM images of Received Material.

sults of the three different processed medium are shown in Figure 10. The microstructure of FSP sample as shown in Figure 10(a) and Figure 10(d), exhibit in the NZ center with fine particles of primary and secondary phases, but the grain sizes are larger than the samples of both SFSP and CFSP. Microstructure of the submerged in water sample is presented in Figure 10(b) and Figure 10(e), Grain development is observed in the NZ center with very fine particles of pri- 

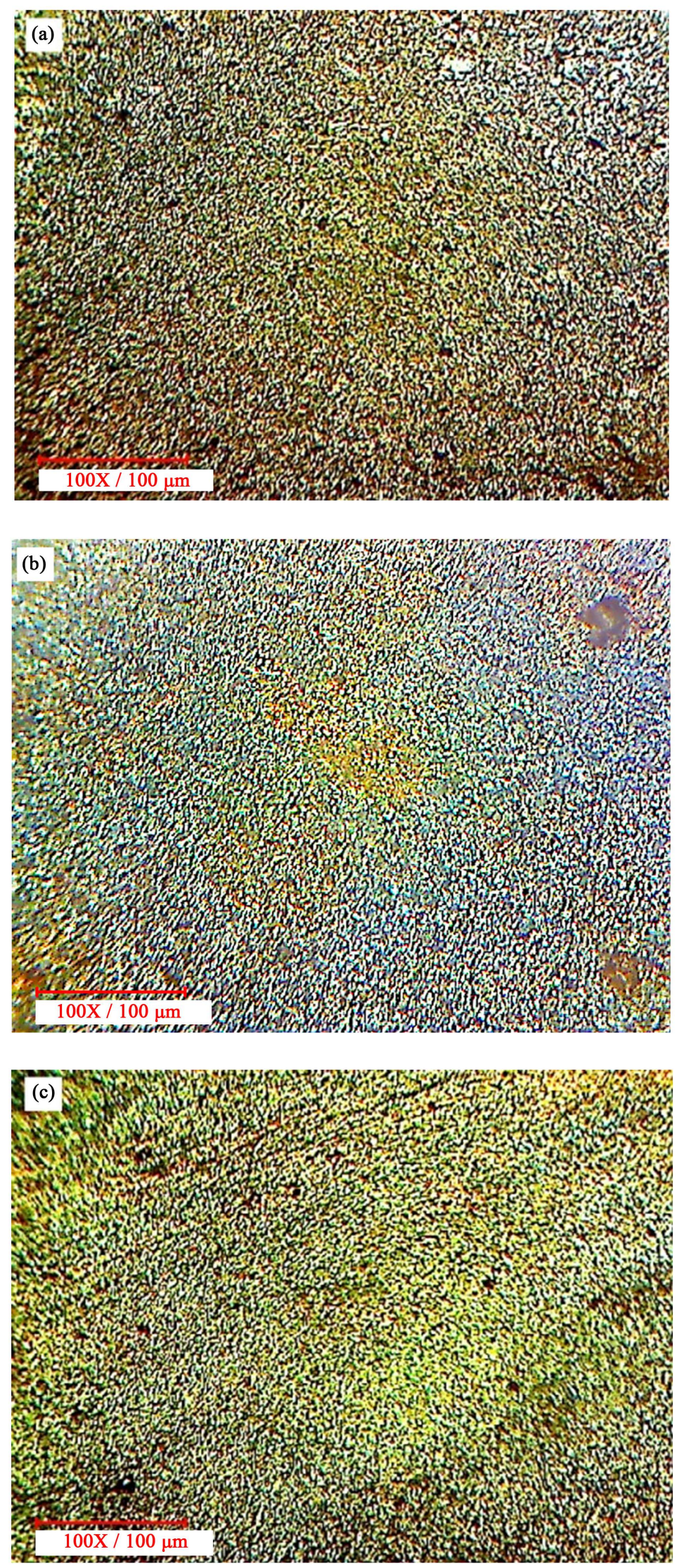

(i) 

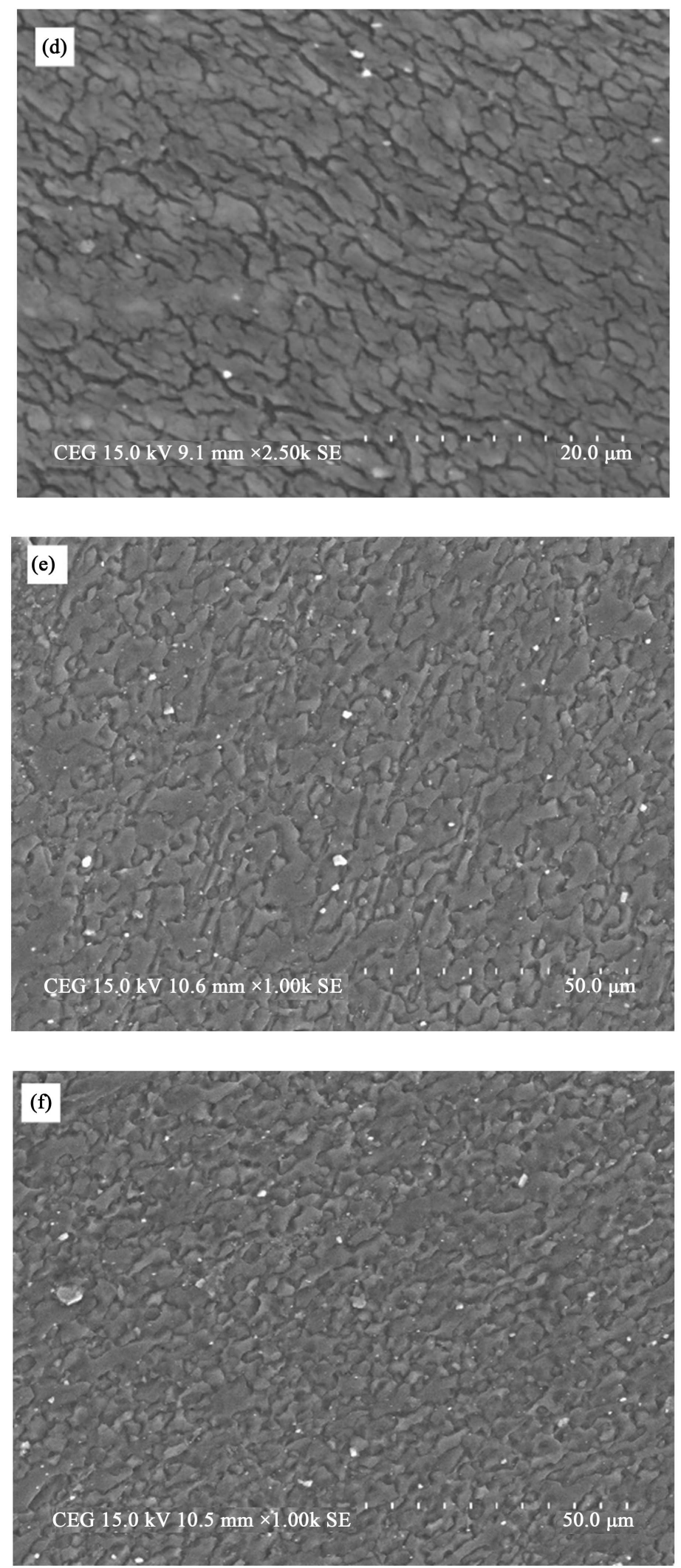

(ii)

Figure 10. Microstructure of FSP, SFSP and CFSP samples. (i) Optical microscope images; (ii) SEM images. 
mary and secondary phases. More grain refinement was achieved under water conditions as was obvious. The grain size alteration also affected by the temperature reduction.

The microstructure of the cryogenic temperature is presented in Figure 10(c) and Figure 10(f). Grain growth in the NZ with complete coagulated grains and can see clearly evidence of super-plasticity due to cryogenic temperature reduction and stress. A higher magnification image by SEM modified the grain arrangement of the material significantly with achievement of the grain alteration. In addition, the average grain size was reduced from more than $62.92 \mu \mathrm{m}$ to as low as $1.92 \mu \mathrm{m}$. FSP also enhanced the homogeneity of the grain structure, and clearly reduced the porosity of the material.

The effect of various temperatures on the resulting microstructure is shown in Figure 10(d) and Figure 10(f). The average grain sizes attained were $18.8 \mu \mathrm{m}$, $2.12 \mu \mathrm{m}$ and $1.92 \mu \mathrm{m}$ for FSP in air, submerged in water and cryogenic coolant respectively. The achievement of a larger grain refinement under cryogenic condition was palpable. The resulting grain size was affected by temperature. The grain size is smaller when the temperature is lower. It is proved to be related to thermal conditions. As discussed in Section 1, the thermal fields are higher sensitive to submerging conditions. They affect not only the peak temperature, but also the time the material spent above a certain temperature. Lower peak temperature and less time spent above a certain temperature lead to smaller grain growth and as a result smaller grain size [26] [27]. In a previous study [8], FSP of magnesium alloy AZ31 was conducted in air and submerged in hot and cold water. The peak temperature and time above a reference temperature showed a considerably decrease compared to the sample processed in air.

The sample submerged in cold water achieved the smallest average grain size of $13.3 \mu \mathrm{m}$ compared to $15.9 \mu \mathrm{m}$ and $18.9 \mu \mathrm{m}$ in FSP samples done in hot water and air, respectively. However, the sample processed in hot water achieved the highest ultimate tensile strength and elongation compared to the other two samples. In another study on cryogenic friction stir processing, Ammouri et al. [10] studied the effects of cryogenic temperature on the microstructure analysis. AZ31B Mg alloy was used in this study where it was FSP in air and FSP in cryogenic coolant (liquid nitrogen). The result indicates the achievement of finer and a homogeneous microstructure when the cryogenic samples are compared to room temperature.

The received microstructure exhibit a combination of large and small grains while the structure of the processed samples show that the majority of grains have almost the same grain size. The finer and more homogenous grain structure produced by FSP is expected to improve the ductility and formability of the material at elevated temperatures and improve its superplastic behavior.

\subsection{Axial Force}

The axial force curves applicable to the three FSP various processed conditions are shown in Figure 11. As revival in the curves no significant differences in the 


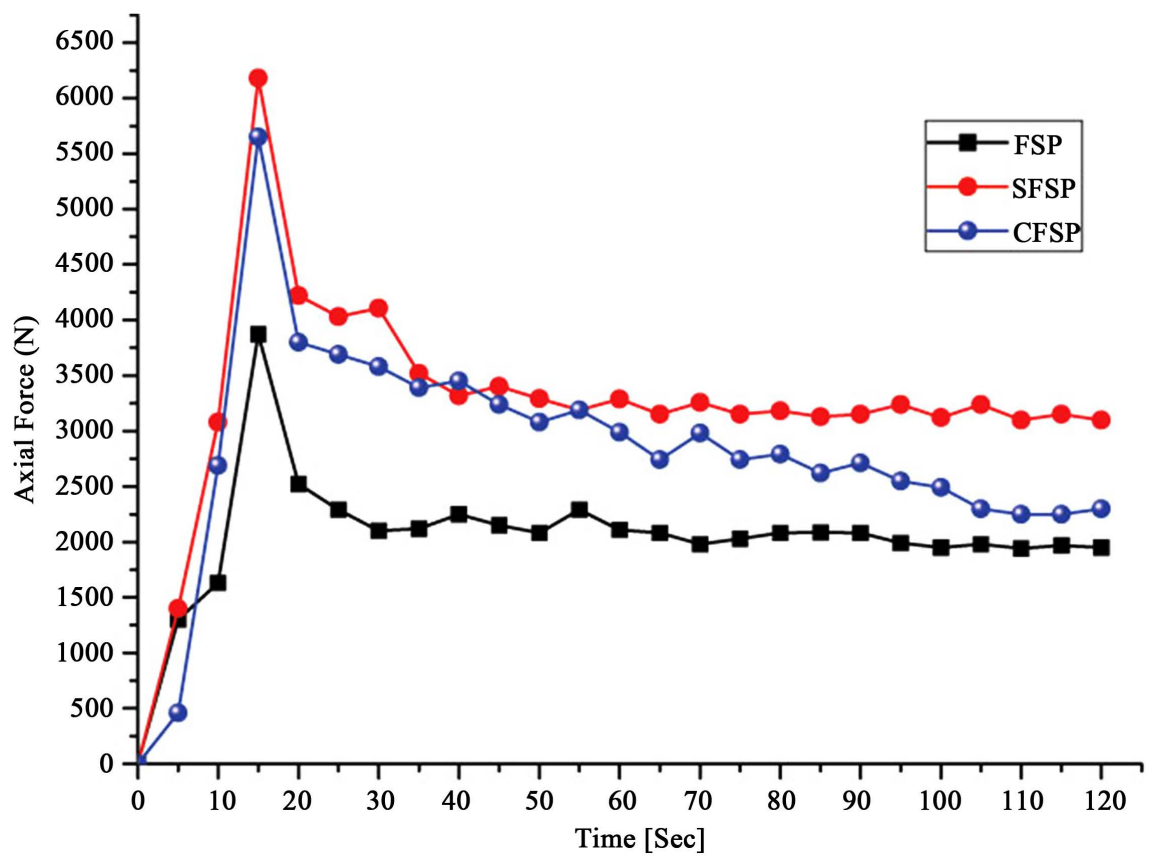

Figure 11. Axial forces of FSP, SFSP and CFSP recorded at constant feed rate $60 \mathrm{~mm} / \mathrm{min}$ and $1000 \mathrm{rpm}$.

axial force were observed, the maximum tool plunged force were $3800 \mathrm{~N}, 6100 \mathrm{~N}$ and $5600 \mathrm{~N}$ for in air, water and cryogenic conditions, consequently. This figure shows, the axial force of the friction stir processed specimens fabricated using cooling is higher than that of the friction stir processed specimen fabricated in air. Moreover, the friction stir processed specimen fabricated using the cooling method of underwater have the highest axial force among other conditions.

The logical conclusion that, by a drop in temperature due to a rise in cooling rate, the FSP axial force increases, whose amount depends on the extent of fall in temperature. This can be attributed to the decrease in material flow when temperature drops. Softening of material leading to a decrease in axial force as a result of the temperature rise during FSP is a fact that gained general acceptance. This account for the stagnant grain development of dynamically recrystallized grains, which would explain the development of very fine grains at the processed NZ under cooling conditions which, in turn, were due to the flow of adequate softened material. This may be the reason for the higher elongation and hardness of the processed samples under cooling conditions compared to in FSP.

The popular belief support the need for a higher degree of cooling for stirring the material at a lower temperature. Axial force has a significant effect on microstructure changes and thereby on micro-hardness. When joining $6 \mathrm{~mm}$ thick butt weld of AZ61 Mg alloy, a micro-hardness value of $84 \mathrm{HV}$ was achieved [28]. Padmanaban et al. [29] have conducted are experiment on axial force on UTS of FSW AZ31B Mg alloy. When the axial force was very low, there heat produced at the bottom of the sample was found insufficient. While, the weld was sound with full diffusion with higher axial force. The result shows the requirement of suffi- 
cient axial force to produce good weld because of the temperature during FSW, the sufficient flow of softened material but the temperature was really dependent on the axial force.

The fragmentation of grains is less due to low axial force, which subsequently results in formation of coarse grains in weld nugget region. If the axial force is too low, the frictional heat generation is reduced, material flow is restricted due to less squeezing action which tends to propagate towards the top surface of the weld nugget. This type of defect is known as a lack of surface fill, unlike the worm hole, the lack of surface fill can be visually detected. [30].

\section{Conclusions}

In this study, Temperature effect and mechanical properties on friction stir processing of AZ31B Mg alloy is investigated by FSP in air, under water and under liquid nitrogen. The following conclusions are arrived.

- Significant grain refinement and porosity reduction are obtained from the Friction Stir Processed specimens.

- Achieving more grain refinement from controlling the thermal boundaries of the process through submerged friction stir processing. It is observed that the specimens were reached at $162^{\circ} \mathrm{C}$ temperature during SFSP.

- Thermal fields of the processed material are highly affected by CFSP. The temperature arrived for the both conditions is measured to be $110^{\circ} \mathrm{C}$.

- FSP improves the elongation of $17.50 \%$ for AZ31B Mg alloy. But SFSP is 23.50\% and CFSP is $26.50 \%$, which are better than FSP.

- Substantial development in the hardness and elongation of the processed material is attained by the grain refinement. The average grain sizes attained were $18.8 \mu \mathrm{m}, 2.12 \mu \mathrm{m}$ and $1.92 \mu \mathrm{m}$ for FSP in air, submerged in water and cryogenic conditions respectively. Under cryogenic conditions more grain refinement is achieved.

- Axial force has been involved in the development of defects, microstructure and hardness of Nugget zone and consequently tensile strength of FSP of AZ31B magnesium alloy with various processed conditions.

\section{References}

[1] Mishra, R.S. and Mahoney, M.W. (2001) Friction Stir Processing: A New Grain Refinement Technique to Achieve High Strain Rate Superplasticity in Commercial Alloys. Materials Science Forum. Trans Tech Publications, Switzerland, 357-359, 507-514. https://doi.org/10.4028/www.scientific.net/MSF.357-359.507

[2] Senthil Kumar, V.S., Lokesh, R., Rathinasuriyan, C. and Shankar, R. (2015) Multi Response Optimization of Submerged Friction Stir Welding Process Parameters Using TOPSIS Approach. IMECE2015-50353:V02BT02A032.

[3] Cui, G.R., Ni, D.R., Ma, Z.Y. and Li, S.X. (2014) Effects of Friction Stir Processing Parameters and In Situ Passes on Microstructure and Tensile Properties of Al-Si-Mg Casting. Metallurgical and Materials Transactions A, 45, 5318-5331. https://doi.org/10.1007/s11661-014-2494-8

[4] Albakri, A.N., Mansour, B., Nasser, H. and Khraisheh, M.K. (2013) Ther- 
mo-Mechanical and Metallurgical Aspects in Friction Stir Processing of AZ31 Mg Alloy A Numerical and Experimental Investigation. Journal of Materials Processing Technology, 213, 279-290. https://doi.org/10.1016/j.jmatprotec.2012.09.015

[5] Padmanaban, G. and Balasubramanian, V. (2009) Selection of FSW Tool Pin Profile, Shoulder Diameter and Material for Joining AZ31B Magnesium Alloy an Experimental Approach. Materials and Design, 30, 2647-2656.

https://doi.org/10.1016/j.matdes.2008.10.021

[6] Chai, F., Zhang, D.T. and Li, Y.Y. (2015) Microstructures and Tensile Properties of Submerged Friction Stir Processed AZ91 Magnesium Alloy. Journal of Magnesium and Alloys, 3, 203-209.

[7] Cao, G.H., Zhang, D.T., Zhang, W. and Qiu, C. (2015) Microstructure Evolution and Mechanical Properties of Mg-Nd-Y Alloy in Different Friction Stir Processing Conditions. Journal of Alloys and Compounds, 636, 12-19. https://doi.org/10.1016/j.jallcom.2015.02.081

[8] Darras, B. and Kishta, E. (2013) Submerged Friction Stir Processing of AZ31 Magnesium Alloy. Materials and Design, 47, 133-137. https://doi.org/10.1016/j.matdes.2012.12.026

[9] Surya Prakash Rao, G. and Balunaik, B. (2015) Effect of Liquid Nitrogen on Friction Stir Welded Joint of Magnesium Alloy Az31b. International Journal of Applied Engineering and Technology, 5, 40-44.

[10] Ammouri, A.H., Kridli, G.T., Ayoub, G. and Hamade, R.F. (2014) Investigating the Effect of Cryogenic Precooling on the Friction Stir Processing of AZ31. Proceedings of the World Congress on Engineering, WCE 2014, 2-4 July 2014, London.

[11] Nomu, V., Devaraju, A. and Shiva Chander, M. (2016) Influence of Liquid Nitrogen Cooling On Microstructure And Mechanical Properties of Friction Stir Welded (FSW) Dissimilar Aa5083-Aa6061 Aluminum Alloy Joints. International Journal of Research in Engineering and Technology, 5, 388-391.

[12] Aruridevarajua, K.V. (2016) Influence of Cryogenic Cooling (Liquid Nitrogen) on Microstructure and Mechanical Properties of Friction Stir Welded 2014-T6 Aluminum alloy. Materials Today, Proceedings.

[13] Rodrigues, D.M., Loureiro, A., Leitao, C., Leal, R.M., Chaparroa, B.M. and Vilaça, P. (2009) Influence of Friction Stir Welding Parameters on the Microstructural and Mechanical Properties of AA 6016-T4 Thin Welds. Materials and Design, 30, 1913-1921. https://doi.org/10.1016/j.matdes.2008.09.016

[14] Darras, B. (2013) Kishta Submerged Friction Stir Processing of AZ31 Magnesium Alloy. Material and Design, 47, 133-137. https://doi.org/10.1016/j.matdes.2012.12.026

[15] Rathinasuriyan, C. and Senthil Kumar, V.S. (2016) Modelling and Optimization of Submerged Friction Stir Welding Parameters for AA6061-T6 Alloy Using RSM. Kovove Mater, 54, 297-304.

[16] Schmidt, H. and Hattel, J. (2005) A Local Model for the Thermomechanical Conditions in Friction Stir Welding. Modelling and Simulation in Materials Science and Engineering, 13, 77-93. https://doi.org/10.1088/0965-0393/13/1/006

[17] Colegrove, P., Shercliff, H. and Zettler, R. (2017) A Model for Predicting the Heat Generation and Temperature in Friction Stir Welding from the Material Properties. Science and Technology of Welding \& Joining, 12, 284-297. https://doi.org/10.1179/174329307X197539

[18] Mishraa, R.S. and Ma, Z.Y. (2005) Friction Stir Welding and Processing. Materials Science and Engineering, R50, 1-78. 
[19] Groza, J.R., Shackelford, J.F., Lavernia, E.J. and Powers, M.T. (2007) Materials Processing Handbook. CRC Press, Boca Raton.

[20] Upadhyay, P. and Reynolds, A.P. (2010) Effects of Thermal Boundary Conditions in Friction Stir Welded AA7050-T7 Sheets. Materials Science and Engineering A, 527, 1537-1543. https://doi.org/10.1016/j.msea.2009.10.039

[21] Hofmann, D.C. and Vecchio, K.S. (2005) Submerged Friction Stir Processing (SFSP) An Improved Method for Creating Ultra-Fine-Grained Bulk Materials. Materials Science and Engineering A, 402, 234-241. https://doi.org/10.1016/j.msea.2005.04.032

[22] Jeong, Y.-H., Hossain, A.M., Hong, S.-T., Sikhan, K., Jinlee, K., Park, J.W. and Han, H.N. (2015) Effects of Friction Stir Processing on the Thermal Conductivity of a Strain-Hardened Al-Mg Alloy. International Journal of Precision Engineering and Manufacturing, 1969-1974.

[23] Hung, F., Shih, C., Chen, L. and Lui, T. (2007) Microstructures and High Temperature Mechanical Properties of Friction Stirred AZ31-Mg Alloy. Journal of Alloys and Compounds, 428, 106-114. https://doi.org/10.1016/j.jallcom.2006.03.066

[24] Chai, F., Zhang, D. and Li, Y. (2014) Effect of Thermal History on Microstructures and Mechanical Properties of AZ31 Magnesium Alloy Prepared by Friction Stir Processing. Journal of Materials Science, 7, 1573-1589.

[25] Padmanaban, G. and Balasubramanian, V. (2009) An Experimental Investigation on Friction Stir Welding of AZ31B Magnesium Alloy. International Journal of Advanced Manufacturing Tech, 49, 111-121.

[26] Xie, G.M. (2011) Effect of Rotation Rate on Microstructures and Mechanical Properties of FSW Mg-Zn-Y-Zr Alloy Joints. Journal of Materials Science \& Technology, 27, 1157-1164. https://doi.org/10.1016/S1005-0302(12)60012-7

[27] Zhang, Z. and Zhang, H.W. (2009) Numerical Studies on Controlling of Process Parameters in Friction Stir Welding. Journal of Materials Processing Technology, 209, 241-270. https://doi.org/10.1016/j.jmatprotec.2008.01.044

[28] Sutton, M., Yang, B., Reynolds, A. and Taylor, R. (2002) Microstructural Studies of Friction Stir Welds in 2024-T3 Aluminum. Materials, Science, Engineering, 323, 160-166.

[29] Razal Rose, A., Manisekar, K. and Balasubramanian, V. (2011) Effect of Axial Force on Microstructure and Tensile Properties of Friction Stir Welded AZ61A Magnesium Alloy. Transactions of Nonferrous Metals Society of China, 21, 974-984. https://doi.org/10.1016/S1003-6326(11)60809-1

[30] Wang, X. and Wang, K. (2016) Micro Structure and Properties of Friction ButtWelded AZ31 Magnesium Alloy. Material Science Engineering, A431, 114-117. 